\title{
Two-parameter Rankine Heat Pumps' COP Equations
}

\author{
A. S. Olawale* and S. S. Adefila \\ Department of Chemical Engineering \\ Ahmadu Bello University, Zaria. Nigeria \\ e-mail: asolawale@yahoo.com, tel: +2348036862485
}

\begin{abstract}
Rankine heat pump coefficient of performance (COPR) equations containing two fit-parameters are reported in this work. The equations can assess the performance of working fluids in vapour compression (Rankine) heat pump without detailed thermodynamic data. These equations contain either temperature term alone or temperature and pressure terms as the only thermodynamic variable(s). The best equation gave error $\leq 6 \%$ over wide range of temperature-lift for different working fluid types that include fluorocarbons, hydrocarbons and inorganic fluids. In these respects the equation performs better than the one-parameter models reported earlier.
\end{abstract}

Keywords: Two parameter equation; Rankine coefficient of performance; vapour compression heat pump; temperature lift variables.

\section{Introduction}

Ideal vapour compression heat pump cycle is also known as Rankine heat pump cycle (Reay, 1979; Holland et al, 1982; Srinivasan et al, 1983; Adefila et al, 1987; Eisa et al, 1991; Jiang et al, 1982; Omideyi et al, 1983). This is because the ideal heat pump is closely approximated by the hypothetical reversed Rankine energy cycle; so its performance is limited by the type of working fluid employed. The coefficient of performance (COP) of ideal vapour compression heat pump (which can be used for quick and preliminary design and analysis of the heat pump as well as screening of environmentally friendly working fluids for the device) is thus termed Rankine COP (COPR). This coefficient is the ratio of enthalpy changes accompanying condensation and compression processes in the heat pump (see Figure 1), but as it has been noted availability of enthalpy data could constitute hindrance to calculating COPR (Olawale and Adefila, 2011). While there are software packages for calculating enthalpy (e.g. Engineering Equation Solver - EES) the routines used in such packages would require more than two parametric values (Olawale and Adefila, 2011).

Attempts have been made in the past to develop equations for calculating ideal $\mathrm{COP}$ for vapour compression heat pump that do not contain enthalpy terms. Most of such equations are working fluid specific and their uses require more than three parametric values (Holland et al,1982; Adefila et al, 1987; Eisa et al, 1991;Jiang et al, 1982; Omideyi et al, 1983). These equations were obtained as polynomials using empirical approach. A simplified COPR equation developed by Patwardhan and Patwardhan (1987) embedded expressions for specific heat capacity and enthalpy of vaporization that contain three or more parameters. COPR models requiring only one parametric value was reported by Olawale and Adefila (2011). The best of these equations was found to hold at conditions up to 0.8 reducing condensing temperature when applied to 18 working fluids. With these equations better accuracy was observed within temperature lift range of 10 to $80 \mathrm{oC}$.
However, COPR equations of this type possessing very high predictive accuracy over a wide range of operating conditions of temperature and pressure are desirable. This is because such would make possible quick calculation of COP for analysis and preliminary design of vapour compression heat pumps with simple calculators; the screening of working fluids which are environmentally friendly can also be carried out in the absence of thermodynamic properties of the fluids. Furthermore, the routines require very small number of data (two at the most) to use in computer-aided calculations or as a part of software package for COP calculations. The necessity thus arises to improve the predictive capability of the equations reported in earlier publication (Holland et al,1982; Adefila et al, 1987; Eisa et al, 1991;Jiang et al, 1982; Omideyi et al, 1983; Olawale and Adefila, 2011; Patwardhan and Patwardhan, 1987).

Therefore this paper reports an attempt to obtain a twoparameter model with better predictive accuracy over a wider condensing and evaporating temperature range than the previous models (Olawale and Adefila, 2011; Patwardhan and Patwardhan, 1987).

\section{Procedure}

The formulated model obtained through transformation of enthalpy fundamental property relation for closed systems by Olawale and Adefila (2011) is:

$\mathrm{COPR}=\left(\frac{2 \mathrm{RZ}_{\mathrm{CO}}}{\mathrm{k}_{\mathrm{H}} \mathrm{P}_{\mathrm{CO}}} \frac{\mathrm{T}_{\mathrm{CO}}}{\left(\mathrm{T}_{\mathrm{CO}}+\mathrm{T}_{\mathrm{EV}}\right)} \frac{\mathrm{T}_{\mathrm{CO}}}{\mathrm{T}_{\mathrm{CO}}-\mathrm{T}_{\mathrm{EV}}}\right)$

where COPR is the Rankine COP, $\mathrm{R}$ is the gas constant, $\mathrm{kH}$ is an unknown constant, ZCO is pseudo-compressibility constant, PCO is condensing pressure and, TCO and TEV are condensing and evaporating temperature respectively. The detail of the derivation of Eq. (1) is given in the Appendix. 


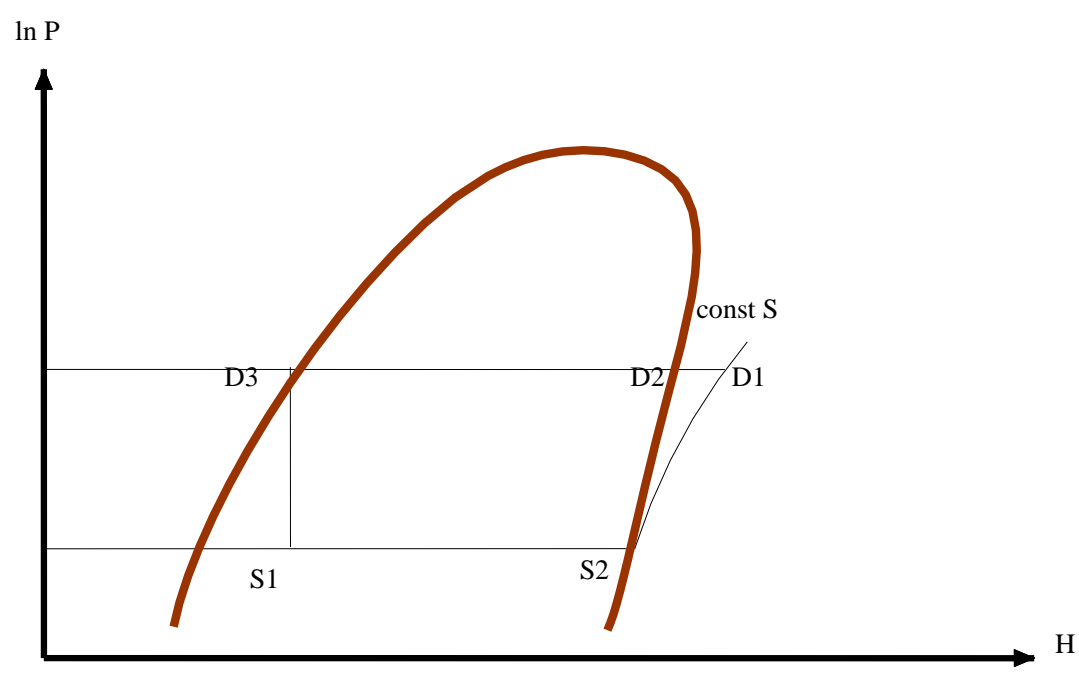

Figure 1. P-H chart of vapour compression heat pump cycle with dry fluid

\subsection{Calibration of the Models}

Calibration of the models involves conversion of the non-intensive unknown quantities in Eq. (1) to intensive variable(s) by simple curve-fitting and parameter estimation of the fits. Two groups were identified from the quantities making up the first term on the RHS of Eq. (1) as: $\mathrm{RZ}_{\mathrm{CO}} / \mathrm{k}_{\mathrm{H}} \mathrm{P}_{\mathrm{CO}}$ (a dimensionless group, called $A K R$.) and $\mathrm{Z}_{\mathrm{CO}} / \mathrm{k}_{\mathrm{H}}$ (a group of two unknown quantities called $A K F$ ). AKR was selected because it is dimensionless and AKF was chosen since it is made up of the two unknown quantities in the equation. By inserting these groups into Eq. (1), we have:

$$
\begin{aligned}
& \mathrm{COPR}=2 \mathrm{AKR} \frac{\mathrm{T}_{\mathrm{CO}}}{\left(\mathrm{T}_{\mathrm{CO}}+\mathrm{T}_{\mathrm{EV}}\right)} \frac{\mathrm{T}_{\mathrm{CO}}}{\mathrm{T}_{\mathrm{CO}}-\mathrm{T}_{\mathrm{EV}}} \\
& \mathrm{COPR}=\frac{2 \mathrm{R} \cdot \mathrm{AKF}}{\mathrm{P}_{\mathrm{CO}}} \frac{\mathrm{T}_{\mathrm{CO}}}{\left(\mathrm{T}_{\mathrm{CO}}+\mathrm{T}_{\mathrm{EV}}\right)} \frac{\mathrm{T}_{\mathrm{CO}}}{\mathrm{T}_{\mathrm{CO}}-\mathrm{T}_{\mathrm{EV}}}
\end{aligned}
$$

Numerical values for AKR and AKF were computed at different evaporating and condensing temperatures and then curve-fitted to eight temperature lift variables as linear, exponential, logarithmic, power and hyperbola functions (David and Wood, 1980; Boehn, 1987); these are twoparameter functions. The temperature lift variables used are (TCO-TEV)TEV, (TCO-TEV)TEV/TC, (TCOEV)TEV/TC2, (TCO-TEV)TEV/TCO, (TCO-TEV) TCO/TCTEV, (TCO- TEV)TEV/TTTCO, (TCO- TEV)/TT and (TCO-TEV)/TC. These temperature lift variables are respectively called VTU, TRV, RDC, DTR, CDT, TDT, DTT and DTC. Fortran program was used to compute COPR, AKR, AKF and the temperature lift variables. COPR was evaluated with Eq. 3, after substituting HD1 with Eqs. 4a and 4b for dry and wet working fluids respectively while Eqs. 2 were used for AKR and AKF after rearrangement.

$$
\begin{aligned}
& \text { COPR }=\frac{\mathrm{H}_{\mathrm{D} 1}-\mathrm{H}_{\mathrm{D} 3}}{\mathrm{H}_{\mathrm{D} 1}-\mathrm{H}_{\mathrm{S} 2}} \\
& \mathrm{H}_{\mathrm{D} 1}=\mathrm{H}_{\mathrm{D} 2}+\left(\theta_{\mathrm{S} 2}-\theta_{\mathrm{D} 2}\right) \mathrm{T}_{\mathrm{CO}} \\
& \mathrm{H}_{\mathrm{D} 1}=\mathrm{H}_{\mathrm{D} 3} \mathrm{X}+\mathrm{H}_{\mathrm{D} 2}(1-\mathrm{X})
\end{aligned}
$$

where (see Figure 1) $\theta_{\mathrm{D} 1}=\theta_{\mathrm{S} 2}=\theta_{\mathrm{D} 3} \mathrm{X}+\theta_{\mathrm{D} 2}(1-\mathrm{X}), \mathrm{X}$ is the liquid fraction of the wet vapour at the final state of isentropic compression $\mathrm{D} 1 ; \mathrm{H}$ and $\theta$ are respectively the mass (specific) enthalpy and entropy of the fluid at the points indicated by the subscripts; subscripts D3 and D2 are the saturation points on the liquid and vapour lines, respectively; subscript D1 is in the superheated and wet regions for dry and wet fluids respectively; D1, D2, and D3 are the points at the heat sink (isobaric condensing line); and S2 stands for the saturation vapour point at the heat source (isobaric evaporating line).

Computations were made for twenty three working fluids, over the range of conditions from the triple point to critical point, using thermodynamic property tables as data sources (Green, 1997; ASHRAE, 1978). The curve-fitting were carried out with Microsoft Excel 2003 and the determination of the fit parameters was done by least square method (David and Wood, 1980; Mickley et al, 1957) using Fortran program. The fit parameters of temperature lift variables that recorded adequate goodness of fit (i.e. with correlation of determination, $\mathrm{R}^{2} \geq 0.9$ ) are given in Table 1 and 2 for AKR and AKF fits respectively. The general forms of resulting expressions for the fits of AKF and AKR to the temperature lift variables are given by Eqs. (5) and (6).

\subsection{Validation of Models}

AKR and AKF fitted linearly to six temperature-lift variables within the range of theoretically feasible operating conditions of vapour compression heat pump (See Figures 2a-d). The fit equations given by Eq. (5) were substituted in Eq. (2a) for AKR to yield Eq. (7); similarly the fit equations for AKF which are given by Eq. (6) replaced AKF in Eq. (2b) to give Eq. (8).

The accuracy and validity of the equations were assessed for twenty three working fluids over the theoretically feasible operating range of vapour compression heat pump. This was done by comparing COP values obtained using Eqs. (7) and (8) with the actual COP values calculated with Eqs. (3) and (4). The parameters used in Eqs. (7) and (8) were determined by least square method; they are presented in Tables 1 and 2. The thermodynamic data used in Eqs (3) and (4) were obtained from thermodynamic properties tables (Green, 1997; ASHRAE, 1978). 


\subsection{Calibration of the Models}

The six temperature lift variables which showed adequate goodness of fit to AKR and AKF are VTU, TRV, RDC, DTR, CDT and TDT. In the feasible operating range (triple to critical point), AKR and AKF did not fit linearly or otherwise to the two other temperature lift variables $\left(\mathrm{R}^{2} \geq 0.95 ;\right.$ adj $\left.\mathrm{R}^{2} \geq 0.90\right)$

$$
\begin{array}{ll}
\mathrm{AKR}=\mathrm{a}_{\mathrm{Ri}} \mathrm{X}_{\mathrm{i}}+\mathrm{b}_{\mathrm{Ri}} & (\mathrm{i}=1 \ldots 6) \\
\mathrm{AKF}=\mathrm{a}_{\mathrm{Fi}} \mathrm{X}_{\mathrm{i}}+\mathrm{b}_{\mathrm{Fi}} & (\mathrm{i}=1 \ldots 6)
\end{array}
$$
given in Eq. (5)-for AKR-and Eq. (6) -for AKF.

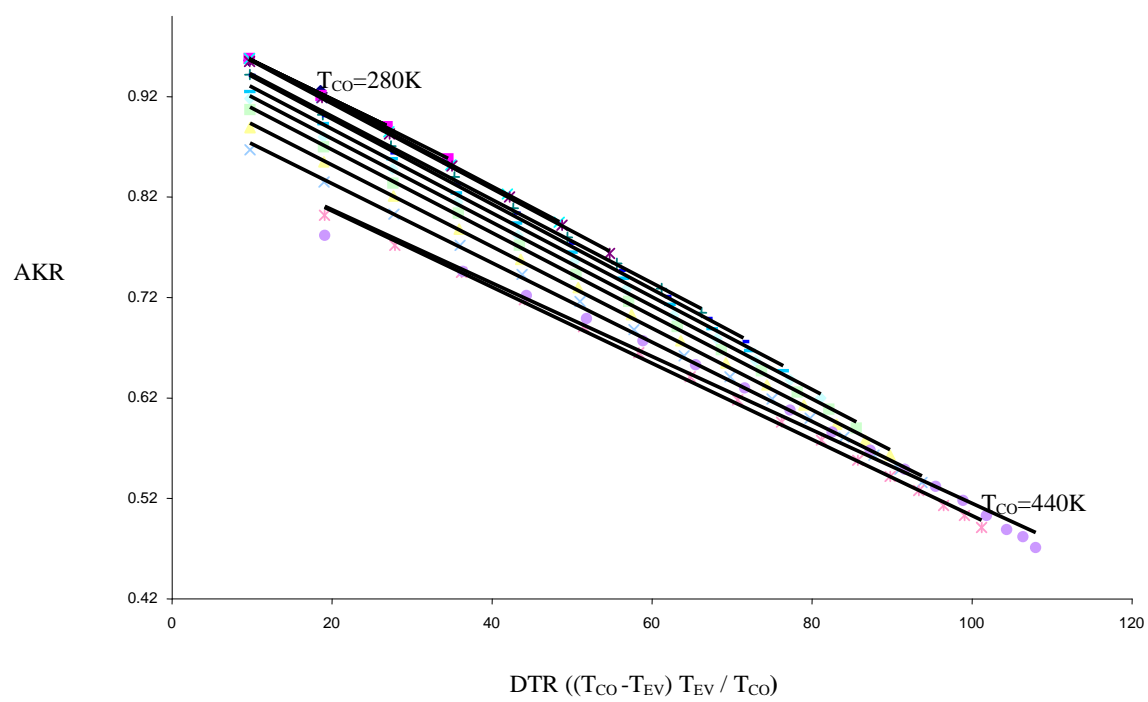

Figure 2a. Condensing isotherms of AKR fitted to DTR for R-21.

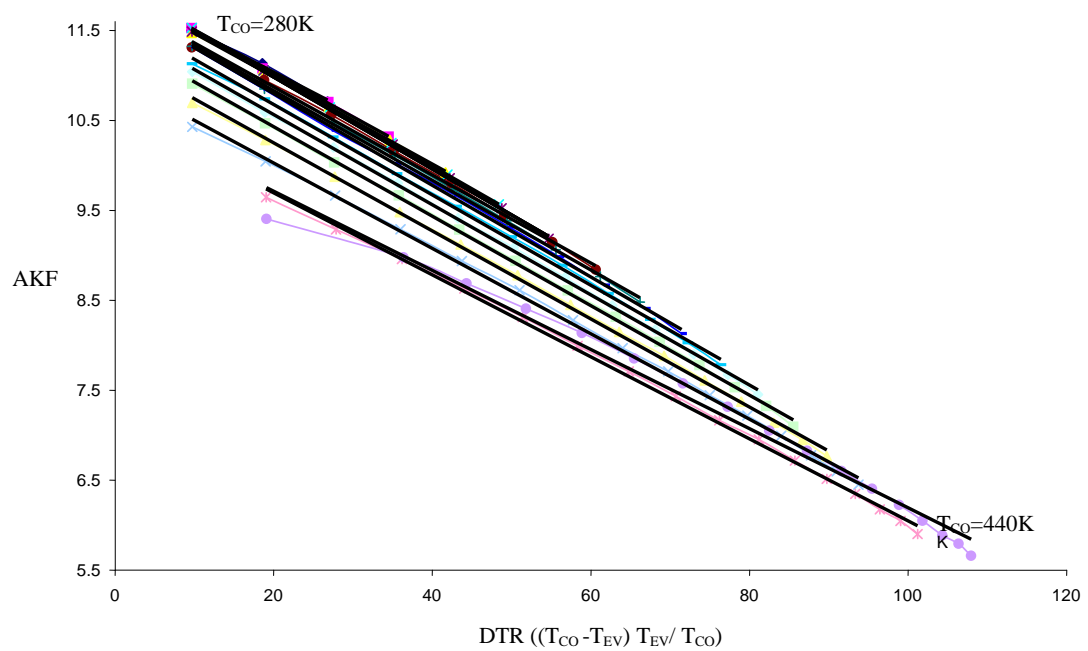

Figure 2b. Condensing isotherms of AKF fitted to DTR for R-21

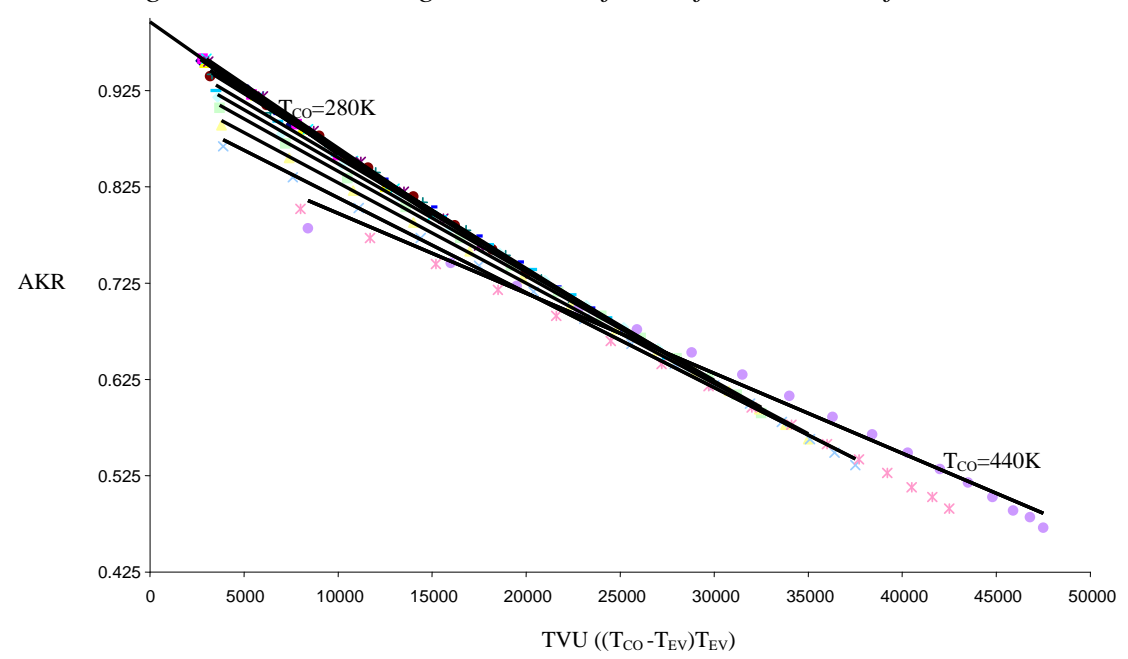

Figure 2c: Condensing isotherms of AKR fitted to VTU for $R-21$. 


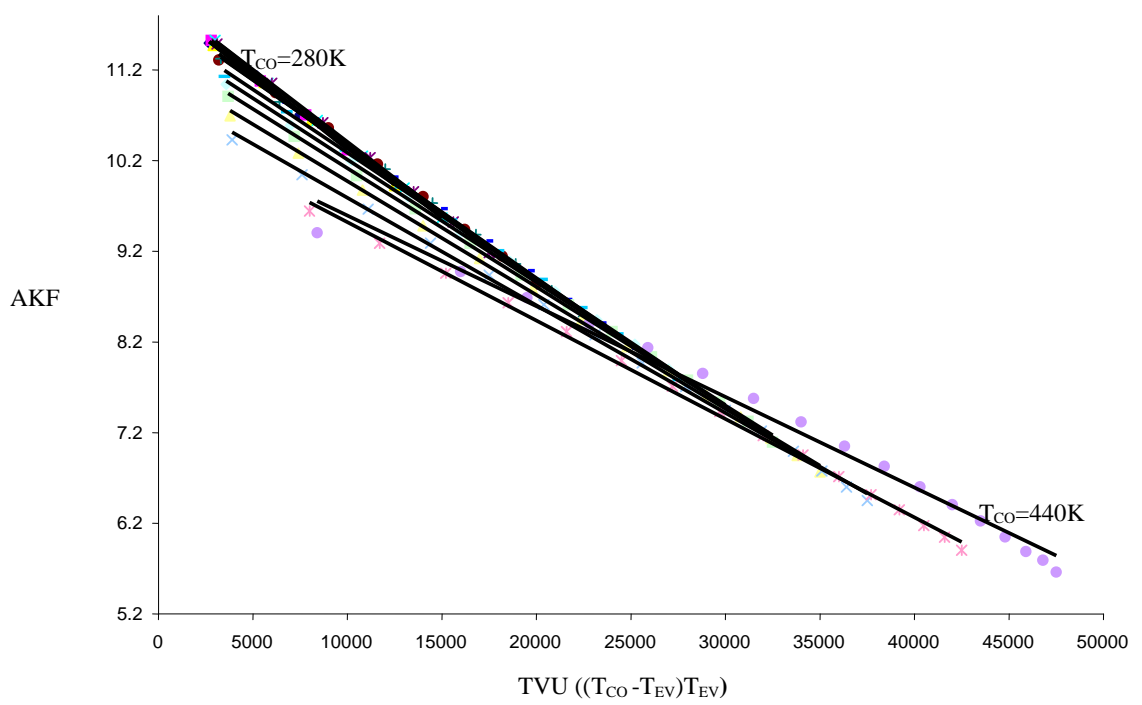

Figure 2d. Condensing isotherms of AKF fitted to VTU for R-21.

Eq, (7) and Eq. (8) are the final forms of the COPR models; they were used for validation purpose in this work.

$$
\begin{aligned}
& \text { COPR }=2\left[\mathrm{a}_{\mathrm{Ri}} \mathrm{X}_{\mathrm{i}}+\mathrm{b}_{\mathrm{Ri}}\right] \frac{\mathrm{T}_{\mathrm{CO}}}{\mathrm{T}_{\mathrm{CO}}+\mathrm{T}_{\mathrm{EV}}} \frac{\mathrm{T}_{\mathrm{CO}}}{\mathrm{T}_{\mathrm{CO}}-\mathrm{T}_{\mathrm{EV}}} \quad(\mathrm{i}=1 \ldots 6) \\
& \mathrm{COPR}=\frac{2 \mathrm{R}}{\mathrm{P}_{\mathrm{CO}}}\left[\mathrm{a}_{\mathrm{Fi}} \mathrm{X}_{\mathrm{i}}+\mathrm{b}_{\mathrm{i}}\right] \frac{\mathrm{T}_{\mathrm{CO}}}{\mathrm{T}_{\mathrm{CO}}+\mathrm{T}_{\mathrm{EV}}} \frac{\mathrm{T}_{\mathrm{CO}}}{\mathrm{T}_{\mathrm{CO}}-\mathrm{T}_{\mathrm{EV}}} \quad(\mathrm{i}=1 \ldots 6)
\end{aligned}
$$

For $\mathrm{i}=1, \mathrm{X}_{1}=\mathrm{VTU}$ and Eqs 7 and 8 become Eqs $7 \mathrm{a}$ and $8 \mathrm{a}$

$$
\begin{aligned}
& \mathrm{COPR}=2\left[\mathrm{a}_{\mathrm{R} 1}\left(\mathrm{~T}_{\mathrm{CO}}-\mathrm{T}_{\mathrm{EV}}\right) \mathrm{T}_{\mathrm{EV}}+\mathrm{b}_{\mathrm{R} 1}\right] \frac{\mathrm{T}_{\mathrm{CO}}}{\mathrm{T}_{\mathrm{CO}}+\mathrm{T}_{\mathrm{EV}}} \frac{\mathrm{T}_{\mathrm{CO}}}{\mathrm{T}_{\mathrm{CO}}-\mathrm{T}_{\mathrm{EV}}} \\
& \mathrm{COPR}=\frac{2 \mathrm{R}}{\mathrm{P}_{\mathrm{CO}}}\left[\mathrm{a}_{\mathrm{F} 1}\left(\mathrm{~T}_{\mathrm{CO}}-\mathrm{T}_{\mathrm{EV}}\right) \mathrm{T}_{\mathrm{EV}}+\mathrm{b}_{\mathrm{F} 1}\right] \frac{\mathrm{T}_{\mathrm{CO}}}{\mathrm{T}_{\mathrm{CO}}+\mathrm{T}_{\mathrm{EV}}} \frac{\mathrm{T}_{\mathrm{CO}}}{\mathrm{T}_{\mathrm{CO}}-\mathrm{T}_{\mathrm{EV}}}
\end{aligned}
$$

where $\mathrm{R}$ is the gas constant for the fluid of interest, $\mathrm{kJ} / \mathrm{kg} . \mathrm{K} ; \mathrm{X}_{\mathrm{i}}$ are the temperature-lift variables; $\mathrm{a}_{\mathrm{Ri}}$ are the slopes and, $b_{\mathrm{Ri}}$ the intercepts, of the linear plots for AKR fits, $\mathrm{a}_{\mathrm{Fi} 6}$ are the slopes and, $\mathrm{b}_{\mathrm{Fi}}$ the intercepts, of the linear plots for AKF fits, .

The two parameters of the AKR- and AKF- linear fits (see Eqs. (5) and (6)) are the slope $\left(\mathrm{a}_{\mathrm{Ri}}\right.$ and $\mathrm{a}_{\mathrm{Fi}}$ ) and the intercept $\left(b_{\mathrm{Ri}}\right.$ and $\left.\mathrm{b}_{\mathrm{Fi}}\right)$. The intercepts for the two sets of fits show similar trend while the fits' slopes also display similar trend. The two linear parameters of the AKR-fits are given in Table 1. The highest intercept value of 1.018 was recorded by R11 (with DTR, CDT and TDT) while the lowest value of 0.928 was shown by R124, R32 and R600a (with VTU, TRV and RDC) for AKR-fit. Each of the twenty-three working fluids investigated recorded similar intercept values for VTU, TRV and RDC and another set of equal intercept value for DTR, CDT and TDT. From these results (see Table 1) it is obvious that the intercept parameter associated with the temperature lift variables containing condensing and evaporating temperature ratio (TR), such as DTR, CDT and TDT have the same intercept value for each working fluid. The other three temperature lift variables which do not contain the temperature ratio (TR) have equal intercept values as well. The intercept values recorded by all the fluids studied for the six temperature lift variable-fits do not vary too widely and averaged to about 0.97 . Considering the small spread in the value of this parameter, it would appear that working fluids' properties do not have significant effect on this parameter.

On the contrary, the large swing in the values of the slope of AKR-linear fits is obvious from Table 1. Only VTU-fit appears to have a relatively smaller variation with the values ranging between -5.0e-6 (for R718) and -1.0e-5 (for R11, R142b and R717). The swing in DTR-fit's slope is moderate if $\mathrm{R} 718(-2.62 \mathrm{e}-4)$ and $\mathrm{RC} 318$ (-1.01e-2) were excluded. The values of this parameter for the rest twentyone fluids vary between $-7.49 \mathrm{e}-3$ (for R114) and -4.07e-3 (for R717). The nature of the fluid obviously has effect on this linear-fit parameter, even though the nature of this influence is not yet clear. The form of the temperature-lift variable used in the curve-fitting is also of significance.

From Table 2, it can be seen that the trends observed with the AKF-fits are similar to that of AKR-fits discussed earlier. The intercept values vary between 11.152 (for R600a) and 12.213 (for R113) and averaged to about 11.65. The equality of the intercept values observed for TVU, TRV and RDC as a set and for DTR, CDT and TDT as another set in Table 1 was also observed for the AKF-fits. The effect of the fluid properties on this parameter appear to be of little or no significant as inferred for AKR-fits.

As with the AKR-fits, the slope $\left(\mathrm{a}_{\mathrm{Fi}}\right)$ values for AKF-fits vary widely among the different fluids and for the six temperature lift variable fits. However, two of the temperature-lift variables fits show minimal swing in values. The slopes of VTU-fit vary between $-1.3 \mathrm{e}-4$ (for R717 and R21) and -5.0e-5 (for R718). The other is DTRfit which vary from $-1.2 \mathrm{e}-1$ (for RC318) to $-3.01 \mathrm{e}-2$ (for R114)

\subsection{Validation of Models}

When the equations were assessed for ability to predict COPR within absolute error range of $0-10 \pm 2.5 \%$, only the six equations containing VTU, DTR and CDT variables performed well. Incidentally these temperature variables do not contain critical temperature (TC). Eq. (8a) (an AKF-fitto-VTU equation) gave $\leq 10 \%$ error in predicting COPR for all the twenty three working fluids up to reduced condensing temperature $(\mathrm{Tr}=\mathrm{TCO} / \mathrm{TC})$ of 0.8 over a wide 
Table 1. Parameters for AKR-fit of Six Temperature-Lift Variables for Some Working Fluids. (Legend below Table 4)

\begin{tabular}{|c|c|c|c|c|c|c|c|c|c|c|c|c|}
\hline \multirow[t]{3}{*}{ Fluids+ } & \multicolumn{12}{|c|}{ Temperature-lift Variables and the fit Parameters } \\
\hline & \multicolumn{2}{|c|}{ VTU } & \multicolumn{2}{|c|}{ TRV } & \multicolumn{2}{|c|}{ RDC } & \multicolumn{2}{|c|}{ DTR } & \multicolumn{2}{|c|}{ CDT } & \multicolumn{2}{|c|}{ TDT } \\
\hline & bR1 & $\mathrm{aR} 1$ & bR2 & $\mathrm{aR} 2$ & bR3 & $\mathrm{aR} 3$ & bR4 & $\mathrm{aR} 4$ & bR5 & aR5 & bR6 & $\mathrm{aR6}$ \\
\hline R113 & .980 & $-2 \mathrm{E}-5$ & .980 & $-5.6 \mathrm{E}-4$ & .980 & $-1.9 \mathrm{E}-2$ & 1.016 & $-7.34 \mathrm{E}-3$ & 1.016 & $-2.504 \mathrm{E}-1$ & 1.016 & -1.7395 \\
\hline R114 & .943 & $-2 \mathrm{E}-5$ & .943 & $-8.03 \mathrm{E}-3$ & .943 & $-3.36 \mathrm{E} 0$ & .982 & $-7.49 \mathrm{E}-3$ & .982 & $-3.138 \mathrm{E}+0$ & .982 & -1.3413 \\
\hline R11 & .970 & $-1 E-5$ & .970 & $-5.98 \mathrm{E}-3$ & .970 & $-2.82 \mathrm{E} 0$ & 1.018 & $-5.73 E-3$ & 1.018 & $-2.699 \mathrm{E}+0$ & 1.018 & -0.9321 \\
\hline R123 & .972 & $-2 E-5$ & .972 & $-5.7 E-4$ & .972 & $-2.11 \mathrm{E}-2$ & .993 & $-6.67 E-3$ & .993 & $-2.446 \mathrm{E}-1$ & .993 & -1.1072 \\
\hline R124 & .928 & $-2 \mathrm{E}-5$ & .928 & $-6.7 E-4$ & .928 & $-2.43 \mathrm{E}-2$ & .938 & $-6.80 \mathrm{E}-3$ & .938 & $-2.463 \mathrm{E}-1$ & .938 & -0.5030 \\
\hline R125 & .964 & $-2 \mathrm{E}-5$ & .964 & $-8.2 \mathrm{E}-4$ & .964 & $-2.96 \mathrm{E}-2$ & .979 & $-7.06 \mathrm{E}-3$ & .979 & $-2.539 \mathrm{E}-1$ & .979 & -1.2184 \\
\hline R12 & .951 & $-2 \mathrm{E}-5$ & .951 & $-6.9 \mathrm{E}-4$ & .951 & $-2.85 \mathrm{E}-2$ & .994 & $-6.07 \mathrm{E}-3$ & .994 & $-2.510 \mathrm{E}-1$ & .994 & -0.7046 \\
\hline R134a & .947 & $-2 \mathrm{E}-5$ & .947 & $-7.7 \mathrm{E}-4$ & .947 & $-3.14 \mathrm{E}-2$ & .956 & $-6.64 \mathrm{E}-3$ & .956 & $-2.698 \mathrm{E}-1$ & .956 & -1.1286 \\
\hline R13b1 & .955 & $-2 \mathrm{E}-5$ & .955 & $-8.1 \mathrm{E}-4$ & .955 & $-3.20 \mathrm{E}-2$ & .980 & $-6.49 \mathrm{E}-3$ & .980 & $-2.572 \mathrm{E}-1$ & .980 & -0.6834 \\
\hline R142b & .952 & $-1 E-5$ & .952 & $-6.1 \mathrm{E}-4$ & .952 & $-2.51 \mathrm{E}-2$ & .971 & $-5.57 \mathrm{E}-3$ & .971 & $-2.295 \mathrm{E}-1$ & .971 & -0.7903 \\
\hline R143a & .948 & $-2 \mathrm{E}-5$ & .948 & $-7.5 \mathrm{E}-4$ & .948 & $-2.88 \mathrm{E}-2$ & .972 & $-6.37 \mathrm{E}-3$ & .972 & $-2.440 \mathrm{E}-1$ & .972 & -1.0303 \\
\hline $\mathrm{R} 152 \mathrm{a}$ & .970 & $-2 \mathrm{E}-5$ & .970 & $-6.9 \mathrm{E}-4$ & .970 & $-3.13 \mathrm{E}-2$ & .997 & $-5.46 \mathrm{E}-3$ & .997 & $-2.466 \mathrm{E}-1$ & .997 & -0.8441 \\
\hline R170 & .935 & $-2 E-5$ & .935 & $-9.5 E-4$ & .935 & $-4.05 \mathrm{E}-2$ & .994 & $-6.84 \mathrm{E}-3$ & .994 & $-2.923 \mathrm{E}-1$ & .994 & -0.6181 \\
\hline R21 & .957 & $-2 \mathrm{E}-5$ & .957 & $-5.4 \mathrm{E}-4$ & .957 & $-2.66 \mathrm{E}-2$ & .981 & $-4.67 \mathrm{E}-3$ & .981 & $-2.309 \mathrm{E}-1$ & .981 & -0.6712 \\
\hline R22 & .947 & $-2 \mathrm{E}-5$ & .947 & $-7.8 \mathrm{E}-4$ & .947 & $-3.87 \mathrm{E}-2$ & .983 & $-5.47 \mathrm{E}-3$ & .983 & $-2.730 \mathrm{E}-1$ & .983 & -0.6332 \\
\hline R23 & .940 & $-2 \mathrm{E}-5$ & .940 & $-9.8 \mathrm{E}-4$ & .940 & $-4.73 E-2$ & .949 & $-5.60 \mathrm{E}-3$ & .949 & $-2.709 \mathrm{E}-1$ & .949 & -0.6608 \\
\hline R290 & .946 & $-2 E-5$ & .946 & $-7.7 \mathrm{E}-4$ & .946 & $-3.25 \mathrm{E}-2$ & .995 & $-6.39 \mathrm{E}-3$ & .995 & $-2.716 \mathrm{E}-1$ & .995 & -0.5490 \\
\hline R32 & .928 & $-2 \mathrm{E}-5$ & .928 & $-8.7 E-4$ & .928 & $-5.04 \mathrm{E}-2$ & .933 & $-4.85 \mathrm{E}-3$ & .933 & $-2.804 \mathrm{E}-1$ & .933 & -0.6611 \\
\hline R600a & .928 & $-2 \mathrm{E}-5$ & .928 & $-6.6 \mathrm{E}-4$ & .928 & $-2.41 \mathrm{E}-2$ & .948 & $-6.66 \mathrm{E}-3$ & .948 & $-2.433 \mathrm{E}-1$ & .948 & -0.7559 \\
\hline R600 & .955 & $-2 E-5$ & .955 & $-6.6 \mathrm{E}-4$ & .955 & $-2.50 \mathrm{E}-2$ & 1.005 & $-6.97 \mathrm{E}-3$ & 1.005 & $-2.645 \mathrm{E}-1$ & 1.005 & -0.9387 \\
\hline R717 & .945 & $-1 \mathrm{E}-5$ & .945 & $-1.21 \mathrm{E}-3$ & .945 & $-1.37 \mathrm{E}-2$ & .963 & $-4.07 \mathrm{E}-3$ & .963 & $-4.617 \mathrm{E}-1$ & .963 & -0.7964 \\
\hline R718 & .959 & $-5 E-6$ & .959 & $-9.4 \mathrm{E}-4$ & .959 & $-2.07 \mathrm{E}-2$ & .986 & $-2.62 \mathrm{E}-4$ & .986 & $-5.796 \mathrm{E}-1$ & .986 & -0.7157 \\
\hline RC318 & .975 & $-3 E-5$ & .975 & $-7.9 \mathrm{E}-4$ & .975 & $-2.18 \mathrm{E}-2$ & .991 & $-1.01 \mathrm{E}-2$ & .991 & $-2.814 \mathrm{E}-1$ & .991 & -2.3637 \\
\hline
\end{tabular}

Table 2. Parameters for AKF-fit of Six Temperature-Lift Variables for Some Working Fluids. (Legend below Table 4)

\begin{tabular}{|c|c|c|c|c|c|c|c|c|c|c|c|c|}
\hline \multirow[t]{3}{*}{ Fluids $^{+}$} & \multicolumn{12}{|c|}{ Temperature-lift Variables and the fit Parameters } \\
\hline & \multicolumn{2}{|c|}{ VTU } & \multicolumn{2}{|c|}{ TRV } & \multicolumn{2}{|c|}{ RDC } & \multicolumn{2}{|c|}{ DTR } & \multicolumn{2}{|c|}{ CDT } & \multicolumn{2}{|c|}{ TDT } \\
\hline & $\mathrm{b}_{\mathrm{F} 1}$ & $\mathrm{a}_{\mathrm{F} 1}$ & $\mathrm{~b}_{\mathrm{F} 2}$ & $\mathrm{a}_{\mathrm{F} 2}$ & $\mathrm{~b}_{\mathrm{F} 3}$ & $\mathrm{a}_{\mathrm{F} 3}$ & $\mathrm{~b}_{\mathrm{F} 4}$ & $a_{F 4}$ & $\mathrm{~b}_{\mathrm{F} 5}$ & $\mathrm{a}_{\mathrm{F} 5}$ & $\mathrm{~b}_{\mathrm{F} 6}$ & $a_{\mathrm{F} 6}$ \\
\hline R113 & 11.780 & $-2.0 \mathrm{E}-4$ & 11.780 & $-6.71 \mathrm{E}-3$ & 11.780 & $-2.29 \mathrm{E}-1$ & 12.213 & $-8.83 \mathrm{E}-2$ & 12.213 & $-3.011 \mathrm{E}+0$ & 12.212 & -20.9233 \\
\hline R114 & 11.341 & $-2.3 \mathrm{E}-4$ & 11.341 & $-9.66 \mathrm{E}-2$ & 11.339 & $-4.04 e+1$ & 11.802 & $-9.01 \mathrm{E}-2$ & 11.800 & $-3.774 \mathrm{E}+1$ & 11.802 & -16.1309 \\
\hline R11 & 11.667 & $-1.5 \mathrm{E}-4$ & 11.667 & $-7.20 \mathrm{E}-2$ & 11.666 & $-3.39 \mathrm{e}+1$ & 12.245 & $-6.89 \mathrm{E}-2$ & 12.244 & $-3.247 \mathrm{E}+1$ & 12.245 & -11.2116 \\
\hline R123 & 11.688 & $-1.9 \mathrm{E}-4$ & 11.688 & $-6.91 \mathrm{E}-3$ & 11.688 & $-2.53 \mathrm{E}-1$ & 11.937 & $-8.02 \mathrm{E}-2$ & 11.937 & $-2.943 \mathrm{E}+0$ & 11.936 & -13.3168 \\
\hline R124 & 11.154 & $-2.2 \mathrm{E}-4$ & 11.154 & $-8.07 \mathrm{E}-3$ & 11.154 & $-2.92 \mathrm{E}-1$ & 11.275 & $-8.17 \mathrm{E}-2$ & 11.274 & $-2.961 \mathrm{E}+0$ & 11.274 & -6.0469 \\
\hline R125 & 11.595 & $-2.8 \mathrm{E}-4$ & 11.595 & $-9.89 \mathrm{E}-3$ & 11.595 & $-3.55 \mathrm{E}-1$ & 11.767 & $-8.50 \mathrm{E}-2$ & 11.767 & $-3.055 \mathrm{E}+0$ & 11.766 & -14.6582 \\
\hline R12 & 11.440 & $-2.0 \mathrm{E}-4$ & 11.440 & $-8.30 \mathrm{E}-3$ & 11.440 & $-3.43 \mathrm{E}-1$ & 11.957 & $-7.30 \mathrm{E}-2$ & 11.957 & $-3.019 \mathrm{E}+0$ & 11.957 & -8.4759 \\
\hline R134a & 11.382 & $-2.3 \mathrm{E}-4$ & 11.382 & $-9.29 \mathrm{E}-3$ & 11.382 & $-3.77 \mathrm{E}-1$ & 11.498 & $-7.99 \mathrm{E}-2$ & 11.498 & $-3.245 \mathrm{E}+0$ & 11.498 & -13.5764 \\
\hline R13b1 & 11.482 & $-2.4 \mathrm{E}-4$ & 11.482 & $-9.70 \mathrm{E}-3$ & 11.482 & $-3.85 \mathrm{E}-1$ & 11.788 & $-7.80 \mathrm{E}-2$ & 11.787 & $-3.093 \mathrm{E}+0$ & 11.787 & -8.2195 \\
\hline R142b & 11.442 & $-1.8 \mathrm{E}-4$ & 11.442 & $-7.33 \mathrm{E}-3$ & 11.442 & $-3.02 \mathrm{E}-1$ & 11.674 & $-6.69 \mathrm{E}-2$ & 11.674 & $-2.760 \mathrm{E}+0$ & 11.674 & $\begin{array}{l}-9.5069 \\
\end{array}$ \\
\hline R143a & 11.404 & $-2.4 \mathrm{E}-4$ & 11.404 & $-9.05 \mathrm{E}-3$ & 11.404 & $-3.47 \mathrm{E}-1$ & 11.684 & $-7.66 \mathrm{E}-2$ & 11.684 & $-2.935 \mathrm{E}+0$ & 11.684 & -12.3931 \\
\hline R152a & 11.662 & $-1.8 \mathrm{E}-4$ & 11.662 & $-8.35 \mathrm{E}-3$ & 11.662 & $-3.77 \mathrm{E}-1$ & 11.992 & $-6.57 \mathrm{E}-2$ & 11.992 & $-2.966 \mathrm{E}+0$ & 11.991 & -10.1513 \\
\hline R170 & 11.239 & $-2.7 \mathrm{E}-4$ & 11.239 & $-1.14 \mathrm{E}-2$ & 11.239 & $-4.87 \mathrm{E}-1$ & 11.949 & $-8.23 \mathrm{E}-2$ & 11.949 & $-3.515 \mathrm{E}+0$ & 11.949 & -7.4347 \\
\hline R21 & 11.503 & $-1.3 \mathrm{E}-4$ & 11.503 & $-6.48 \mathrm{E}-3$ & 11.503 & $-3.20 \mathrm{E}-1$ & 11.796 & $-5.62 \mathrm{E}-2$ & 11.796 & $-2.777 \mathrm{E}+0$ & 11.795 & -8.0746 \\
\hline R22 & 11.390 & $-1.9 \mathrm{E}-4$ & 11.390 & $-9.33 \mathrm{E}-3$ & 11.390 & $-4.66 \mathrm{E}-1$ & 11.813 & $-6.58 \mathrm{E}-2$ & 11.813 & $-3.283 \mathrm{E}+0$ & 11.813 & -7.6142 \\
\hline R23 & 11.307 & $-2.4 \mathrm{E}-4$ & 11.307 & $-1.17 \mathrm{E}-2$ & 11.307 & $-5.69 \mathrm{E}-1$ & 11.407 & $-6.74 \mathrm{E}-2$ & 11.407 & $-3.259 \mathrm{E}+0$ & 11.407 & -7.9497 \\
\hline R290 & 11.371 & $-2.2 \mathrm{E}-4$ & 11.371 & $-9.21 \mathrm{E}-3$ & 11.371 & $-3.91 \mathrm{E}-1$ & 11.969 & $-7.69 \mathrm{E}-2$ & 11.969 & $-3.268 \mathrm{E}+0$ & 11.969 & -6.6052 \\
\hline R32 & 11.157 & $-1.8 \mathrm{E}-4$ & 11.157 & $-1.05 \mathrm{E}-2$ & 11.157 & $-6.06 \mathrm{E}-1$ & 11.218 & $-5.83 \mathrm{E}-2$ & 11.218 & $-3.372 \mathrm{E}+0$ & 11.218 & -7.9507 \\
\hline R600a & 11.152 & $-2.2 \mathrm{E}-4$ & 11.152 & $-7.93 \mathrm{E}-3$ & 11.152 & $-2.90 \mathrm{E}-1$ & 11.395 & $-8.01 \mathrm{E}-2$ & 11.395 & $-2.926 \mathrm{E}+0$ & 11.395 & -9.0913 \\
\hline R600 & 11.484 & $-2.1 \mathrm{E}-4$ & 11.484 & $-7.92 \mathrm{E}-3$ & 11.484 & $-3.01 \mathrm{E}-1$ & 12.078 & $-8.38 \mathrm{E}-2$ & 12.078 & $-3.181 \mathrm{E}+0$ & 12.078 & -11.3020 \\
\hline R717 & 11.367 & $-1.3 \mathrm{E}-4$ & 11.367 & $-1.45 \mathrm{E}-2$ & 11.367 & $-1.65 \mathrm{E}-1$ & 11.581 & $-4.90 \mathrm{E}-2$ & 11.580 & $-5.553 \mathrm{E}+0$ & 11.580 & -9.5789 \\
\hline R718 & 11.525 & $-5.0 \mathrm{E}-5$ & 11.525 & $-1.12 \mathrm{E}-2$ & 11.525 & $-2.49 \mathrm{e}+0$ & 11.852 & $-3.15 \mathrm{E}-2$ & 11.852 & $-6.970 \mathrm{E}+0$ & 11.852 & -8.6075 \\
\hline RC318 & 11.729 & $-3.4 \mathrm{E}-4$ & 11.729 & $-9.45 \mathrm{E}-3$ & 11.729 & $-2.62 \mathrm{E}-1$ & 11.913 & $-1.21 \mathrm{E}-1$ & 11.913 & $-3.385 \mathrm{E}+0$ & 11.912 & -28.4345 \\
\hline
\end{tabular}

temperature lift range. Eq. (7), an AKR-fit-to-VTU equation, performed as well for twenty fluids. Eqs. (8a) and (7a) can thus find use for engineering applications, since errors as high as $10 \%$ are known to be acceptable (Jin and Splitter, 2002; Poling et al., 2001)

Predictive accuracies of the best four of the twelve equations validated are presented in Table 3. From these results it is seen that Eq. (8a) predicts $\mathrm{COPR}$ at $\operatorname{Tr} \leq 0.7$ with absolute error of between 0 and $6 \%$ for 20 of the 23 working fluids investigated. For the same accuracy range, Eq. (7a) was adequate for 13 fluids while the other two equations predicted for seven fluids only. In comparison term, Eq. (8a) is the best when predictive accuracy of $95 \%$ (and higher) are considered. Equations containing TDT variables were observed to give the same predictive accuracies as those containing DTR though the parameters of these temperature lift variables (for AKR and AKF-fits) are not the same (see Tables 1 and 2). This similarity in computational accuracy arose probably because triple temperature (TT), which is a constant, is the only difference between these two temperature lift variables.

As seen from Table 4, Eq. 8a (which contains VTU-fitof-AKF) is still the best equation when the predictive ability over wider temperature lift range and performance in the neighbourhood of critical point are considered. In term of performance at $\operatorname{Tr} \leq 0.8$, the range of absolute error is typically between 0 and $6 \%$ for temperature lift ranging between 10 and $800 \mathrm{C}$. For a wider range of temperature lift (see column 5 of Table 4), only R600a and RC318 recorded absolute error greater than $10 \%$. It would appear that the specification of condensing pressure (PCO), in addition to evaporating and condensing temperatures, improves the 
Table 3. Error ${ }^{a}$ up to $6 \%$ of the 4 Best Models with Reduced Condensing Temperature (Tr) Limits.

\begin{tabular}{|c|c|c|c|c|c|c|c|c|}
\hline \multirow{2}{*}{ Fluids $^{+}$} & \multicolumn{9}{|c|}{ Temperature-lift Variable Fits of the Models } \\
\cline { 2 - 9 } & VTUa & \multicolumn{2}{|c|}{ VTUb } & \multicolumn{2}{c|}{ DTRa } & \multicolumn{2}{c|}{ DTRb } \\
\cline { 2 - 9 } & Error & Tr & Error & Tr & Error & Tr & Error & Tr \\
\hline R113 & $(6.25)$ & 0.59 & 5.88 & 0.74 & $(7.81)$ & 0.57 & $(7.89)$ & 0.57 \\
\hline R114 & 5.98 & 0.71 & 5.08 & 0.79 & $(9.04)$ & 0.50 & $(9.13)$ & 0.59 \\
\hline R11 & $(7.87)$ & 0,55 & 5.33 & 0.89 & $(6.54)$ & 0.64 & $(6.63)$ & 0.64 \\
\hline R123 & $(12.2)$ & 0.68 & 5.74 & 0.79 & $(12.2)$ & 0.68 & $(12.3)$ & 0.68 \\
\hline R124 & $(8.02)$ & 0.66 & $(7.23)$ & 0,66 & $(11.6)$ & 0.66 & $(11.7)$ & 0.66 \\
\hline R125 & 5.19 & 0.85 & 5.09 & 0.85 & $(8.19)$ & 0.68 & $(8.28)$ & 0.68 \\
\hline R12 & 5.82 & 0.67 & 4.46 & 0.91 & $(6.19)$ & 0.65 & $(6.17)$ & 0.65 \\
\hline R134a & $(7.52)$ & 0.66 & 5.58 & 0.73 & $(8.46)$ & 0.66 & $(8.97)$ & 0.66 \\
\hline R13b1 & 4.26 & 0.88 & 4.30 & 0.88 & $(6.15)$ & 0.62 & $(6.13)$ & 0.62 \\
\hline R142b & $(6.78)$ & 0.65 & 4.88 & 0.90 & $(7.23)$ & 0.56 & $(7.27)$ & 0.56 \\
\hline R143a & 4.97 & 0.84 & 5.43 & 0.87 & $(6.85)$ & 0.61 & $(6.91)$ & 0.61 \\
\hline R152a & 5.18 & 0.60 & 4.68 & 0.88 & 5.52 & 0.57 & 5.52 & 0.57 \\
\hline R170 & $(6.77)$ & 0,46 & 5.47 & 0.46 & 5.56 & 0.66 & 5.64 & 0.66 \\
\hline R21 & 5.38 & 0.81 & 5.44 & 0.88 & 5.20 & 0.85 & 5.17 & 0.85 \\
\hline R22 & 5.51 & 0.60 & 5.17 & 0.70 & 5.68 & 0.87 & 5.73 & 0.90 \\
\hline R23 & 5.14 & 0.90 & 5.12 & 0.90 & $(6.92)$ & 0.70 & $(6.99)$ & 0.70 \\
\hline R290 & 5.37 & 0.62 & 5.97 & 0.52 & 5.46 & 0.57 & 5.47 & 0.57 \\
\hline R32 & $(8.34)$ & 0.65 & 5.89 & 0.85 & $(8.51)$ & 0.65 & $(8.55)$ & 0.65 \\
\hline R600a & $(6.93)$ & 0.54 & $(6.27)$ & 0.54 & $(13.6)$ & 0.54 & $(13.6)$ & 0.54 \\
\hline R600 & 4.27 & 0.61 & 5.42 & 0.73 & $(6.98)$ & 0.49 & $(7.07)$ & 0.49 \\
\hline R717 & 4.55 & 0.91 & 4.78 & 0.91 & 5.42 & 0.91 & 5.24 & 0.72 \\
\hline R718 & 5.04 & 0.74 & 5.35 & 0.90 & 5.67 & 0.90 & 4.66 & 0.85 \\
\hline RC318 & $(7.15)$ & 0.69 & $(10.3)$ & 0.72 & $(11.3)$ & 0.69 & $(11.9)$ & 0.69 \\
\hline
\end{tabular}

a - $\quad$ errors out of desired range in parenthesis ().

Table 4. Error range of the 2 Best Equations over Practical and Maximum Temperature lift Ranges.

\begin{tabular}{|c|c|c|c|c|c|c|}
\hline \multirow{3}{*}{ Fluids $^{+}$} & \multicolumn{2}{|c|}{ Equation $7 \mathrm{a}$} & \multicolumn{2}{|c|}{ Equation 8a } & \multirow{3}{*}{$\begin{array}{c}\text { Highest } \\
\text { Tr }\end{array}$} & \multirow[t]{3}{*}{$\operatorname{MaxT}_{\mathrm{L}},{ }^{0} \mathrm{C}$} \\
\hline & \multicolumn{4}{|c|}{ Error ranges associated with ranges of temperature lifts } & & \\
\hline & $10-80^{\circ} \mathrm{C}^{*}$ & $\begin{array}{l}10- \\
\operatorname{MaxT}_{\mathrm{L}}{ }^{0} \mathrm{C}\end{array}$ & $10-80^{\circ} \mathrm{C}^{*}$ & $10-\operatorname{MaxT}_{\mathrm{L}}{ }^{0} \mathrm{C}$ & & \\
\hline R113 & $1.74->10$ & $1.74->30$ & $0.13-6.95$ & $0.13-8.53$ & 0.800 & 150 \\
\hline R114 & $2.10-8.03$ & $2-10->10$ & $0.41-5.08$ & $0.41-6.15$ & 0.812 & 150 \\
\hline $\mathrm{R} 11$ & $0.09-7.45$ & $0.09->10$ & $0.05-2.95$ & $0.09-3.69$ & 0.807 & 180 \\
\hline R123 & $1.44->15$ & $1.44->10$ & $0.14-6.66$ & $0.14-7.70$ & 0.819 & 124.4 \\
\hline R124 & $4.72->10$ & $4.72->10$ & $4.23-9.77$ & $4.23-10.03$ & 0.817 & 90 \\
\hline R125 & $0.18-4.33$ & $0.18-4.33$ & $0.157-4.47$ & $0.157-4.47$ & 0.825 & 80 \\
\hline R12 & $0.22->10$ & $0.22->10$ & $0.07-6.02$ & $0.07-6.02$ & 0.805 & 160 \\
\hline R134a & $1.40->10$ & $1.40->10$ & $1.20-8.37$ & $1.20-8.37$ & 0.814 & 71.8 \\
\hline R13b1 & $0.13-4.26$ & $0.02-4.26$ & $0.16-4.30$ & $0.11-4.30$ & 0.823 & 110 \\
\hline R142b & $0.01-9.96$ & $0.01->10$ & $1.81-4.26$ & $1.81-4.66$ & 0.804 & 130 \\
\hline R143a & $0.60-4.91$ & $0.60-4.91$ & $0.53-4.88$ & $0.53-4.88$ & 0.807 & 110 \\
\hline R152a & $2.01->10$ & $2.01->10$ & $0.11-2.63$ & $0.11-2.63$ & 0.802 & 140 \\
\hline $\mathrm{R} 170$ & $0.17->10$ & $0.17->10$ & $0.17-6.08$ & $0.17-7.12$ & 0.819 & 150 \\
\hline R21 & $0.03-3.28$ & $0.03-6.05$ & $0.02-3.60$ & $0.02-3.60$ & 0.809 & 120 \\
\hline R22 & $1.03->10$ & $1.03>10$ & $0.09-5.06$ & $0.09-5.06$ & 0.812 & 150 \\
\hline R23 & $2.08-5.14$ & $2.08-5.14$ & $0.01-5.12$ & $0.01-5.12$ & 0.802 & 60 \\
\hline R290 & $0.06-10.13$ & $0.06->10$ & $0.19-7.40$ & $0.19-7.75$ & 0.811 & 170 \\
\hline R32 & $6.04->10$ & $6.04->10$ & $4.12-6.16$ & $4.33-6.26$ & 0.797 & 80 \\
\hline R600a & $3.95->10$ & $3.95->10$ & $0.41-8.89$ & $0.41->10$ & 0.809 & 170 \\
\hline R600 & $0.10->10$ & $0.10->10$ & $0.16-6.80$ & $0.16-7.71$ & 0.800 & 180 \\
\hline R717 & $0.06-4.55$ & $0.06-4.55$ & $0.10-4.78$ & $0.00-4.78$ & 0.814 & 130 \\
\hline R718 & $0.09-6.13$ & $0.09-7.63$ & $0.04-4.48$ & $0.04-6.25$ & 0.803 & 240 \\
\hline RC318 & $1.97->10$ & $1.97->10$ & $0.34->10$ & $0.34->10$ & 0.798 & 70 \\
\hline
\end{tabular}

Legend for Tables 1 - 4

$+\quad$-ASHRAE Code, * - Temperature lift of between 10 and $80^{\circ} \mathrm{C}$; ca -circa (about

$\operatorname{MaxT}_{\mathrm{L}}$ - Maximum temperature lift achieved; $\mathrm{Tr}$-reduced condensing temperature

$\mathrm{a}_{\mathrm{Ri}} \quad$-slope of the linear plot to AKR-fits $(i=1, \ldots, 6)$,

$\mathrm{a}_{\mathrm{Fi}} \quad$-slope of the linear plot to AKF-fits $(i=1 \ldots, 6)$

$b_{\mathrm{Ri}} \quad$-intercept of the linear plot to AKR-fits $(\mathrm{i}=1, \ldots, 6)$;

$\mathrm{b}_{\mathrm{Fi}} \quad$-intercept of the linear plot to AKF-fits $(\mathrm{i}=1, \ldots, 6)$

$\begin{array}{lllll}\text { VTU } & -\left(\mathrm{T}_{\mathrm{CO}}-\mathrm{T}_{\mathrm{EV}}\right) \mathrm{T}_{\mathrm{EV}} & (\mathrm{i}=1) ; \mathrm{TRV} & -\left(\mathrm{T}_{\mathrm{CO}}-\mathrm{T}_{\mathrm{EV}}\right) \mathrm{T}_{\mathrm{EV}} / \mathrm{T}_{\mathrm{C}} & \text { (i=2) } \\ \mathrm{RDC} & -\left(\mathrm{T}_{\mathrm{CO}}-\mathrm{T}_{\mathrm{EV}}\right) \mathrm{T}_{\mathrm{EV}} / \mathrm{T}_{\mathrm{C}}{ }_{\mathrm{CO}} & (\mathrm{i}=3) ; \mathrm{DTR} & -\left(\mathrm{T}_{\mathrm{CO}}-\mathrm{T}_{\mathrm{EV}}\right) \mathrm{T}_{\mathrm{EV}} / \mathrm{T}_{\mathrm{CO}} & \text { (i=4) } \\ \mathrm{CDT} & -\left(\mathrm{T}_{\mathrm{CO}}-\mathrm{T}_{\mathrm{EV}}\right) \mathrm{T}_{\mathrm{CO}} / \mathrm{T}_{\mathrm{C}} \mathrm{T}_{\mathrm{EV}} & (\mathrm{i}=5) ; \mathrm{TDT} & -\left(\mathrm{T}_{\mathrm{CO}}-\mathrm{T}_{\mathrm{EV}}\right) \mathrm{T}_{\mathrm{EV}} / \mathrm{T}_{\mathrm{T}} \mathrm{T}_{\mathrm{CO}} & \text { (i=6) }\end{array}$ 
predictive ability of these intensive-variable-based twoparameter COPR models. This appears to be more so if the temperature lift variable utilized in the equations has evaporating temperature (TEV) as the only non-linear term.

The results presented in Table 4 show that Eq. (8a) gives lower error limit for COPR prediction than $3 \%$ reported by Patwardhan and Patwardhan (1987). Even then the latter equation requires greater number of parametric data to use. In comparison to the one-parameter equation reported by Olawale and Adefila (2011), three differences are obvious. First, more working fluids which include inorganic fluids (i.e. R717 and R718) are adequately predicted with Equation 8a yet the upper error limit in the practical temperature lift range (10-800C) are similar for the two models. Secondly, the equation gives absolute error range between 0 and $10 \%$ over a wider temperature lift range than was possible with one-parameter COPR equation. The third difference is that the equation records absolute error $\leq 5 \%$ in the proximity of critical point for many of the fluids; and unlike the case with one-parameter model, the predictive accuracy was not necessarily reducing with increasing condensing and evaporating temperature.

\section{Conclusions}

Generalised models for COP of ideal vapour compression heat pumps with two fit-parameters were developed in this work. Some of these models showed adequate predictive capacity for COPR in the useful temperature lift range and beyond. The model based on VTU is useful for more accurate COPR calculation. The required condensing pressure data could be easily obtained with P-T correlations such as Antoine equation... Since these models require minimal number of data to use they are useful for quick analysis and preliminary design of heat pump with computer or simple calculator. They can also be of value in thermodynamic assessment of new working fluids to replace CFCs and HCFCs, where there is little or no thermodynamic data. The models can be modified to include irreversibility terms (due to compression, condensation and evaporation) to estimate COP for real vapour compression heat pump.

\section{Nomenclature}

$a_{F 1}-a_{F 6}, a_{R 1}-a_{R 6}-$ Parameters (slopes) of the Fits

$b_{\mathrm{F} 1-} b_{\mathrm{F} 6}, b_{\mathrm{R} 1-} b_{\mathrm{R} 6}$ - Parameters (Intercepts) of the Fits

AKF

AKR

CDT

Acronym for unknown $\mathrm{Z}_{\mathrm{CO}} / \mathrm{k}_{\mathrm{H}}$

- Acronym for $\mathbf{R} \mathbf{Z}_{\mathrm{CO}} / \mathbf{k}_{\mathbf{H}} \mathbf{P}_{\mathrm{CO}}$

COP

COPR

DTR-

$\mathrm{H}$

$\mathrm{H}_{\mathrm{D} 1}$

$\mathrm{H}_{\mathrm{D} 2}$

$\mathrm{H}_{\mathrm{D} 3}$

HFC

$\mathrm{H}_{\mathrm{S} 2}$

$\mathrm{k}_{\mathrm{H}}$

$\mathrm{P}$
$\mathrm{P}_{\mathrm{CO}}$

$\mathrm{R}$

RDC

S

$\mathrm{T}$

$\mathrm{T}_{\mathrm{CO}}$

$\mathrm{T}_{\mathrm{EV}}$

TDT

TRV

VTU

$\mathrm{Z}_{\mathrm{CO}}$

Greek symbols
$\partial$
$\theta$
$\theta_{\mathrm{D} 1}$
$\theta_{\mathrm{D} 2}$
$\theta_{\mathrm{D} 3}$
$\theta_{\mathrm{S} 2}$

- Condensing Pressure, bar or $\mathrm{kPa}$

- Universal Gas Constant, kJ/kg. ${ }^{\circ} \mathrm{C}$

- Acronym for temperature-lift variable given as $\left(\mathrm{T}_{\mathrm{CO}}-\mathrm{T}_{\mathrm{EV}}\right) \mathrm{T}_{\mathrm{EV}} / \mathrm{T}_{\mathrm{C}}$

- Specific Entropy, kJ/kg.

- Temperature, ${ }^{\circ} \mathrm{C}$ or $\mathrm{K}$

- Condensing Temperature, ${ }^{\circ} \mathrm{C}$ or $\mathrm{K}$

- Evaporating Temperature, ${ }^{\circ} \mathrm{C}$ or $\mathrm{K}$

- Acronym for temperature-lift variable given as $\left(\mathrm{T}_{\mathrm{CO}}-\mathrm{T}_{\mathrm{EV}}\right) \mathrm{T}_{\mathrm{EV}} / \mathrm{T}_{\mathrm{CO}} \mathrm{T}_{\mathrm{T}}$

- Acronym for temperature-lift variable given as $\left(\mathrm{T}_{\mathrm{CO}}-\mathrm{T}_{\mathrm{EV}}\right) \mathrm{T}_{\mathrm{EV}} / \mathrm{T}_{\mathrm{C}}$

- Acronym for temperature-lift variable given as $\left(\mathrm{T}_{\mathrm{CO}}-\mathrm{T}_{\mathrm{EV}}\right) \mathrm{T}_{\mathrm{EV}}$

- Pseudo-compressibility Factor at Condensing Condition

- Partial Differential

- $\quad$ Specific Entropy, kJ/kg.K

- Specific Entropy of Wet Vapour at Isobaric Condensation, $\mathrm{kJ} / \mathrm{kg}$

- Specific Entropy of Saturated Liquid at Isobaric Condensation, $\mathrm{kJ} / \mathrm{kg}$

- Specific Entropy of Saturated Vapour at Isobaric Condensation, $\mathrm{kJ} / \mathrm{kg}$

- Specific Entropy of Saturated Vapour at Isobaric Vaporisation, $\mathrm{kJ} / \mathrm{kg}$

\section{References}

Adefila, S. S., Devotta, S., Watson, F. A., Holland, F. A. (1987). Derived Thermodynamic Design Data for Heat Pump Systems operating on R717. Journal of Heat Recovery Systems, 3(1), 11-17.

ASHRAE, (1978). ASHRAE Handbook and Product Directory: 1977 Fundamental, New York, NY: ASHRAE.

Boehm, R. F. (1987). Design Analysis of Thermal Systems, New York, NY: John Wiley and Sons Inc. pp 231 237.

David, C., Wood, R. F. (1980). Fitting Equations to Data $\left(2^{\text {nd }}\right.$ ed.), New York, N.Y.: John Wiley and Sons Inc.

Eisa, M. A. R., Abdel Rahman, K., Holland, F. A. (1991). Derived Thermodynamic Design Data for Heat Pump Systems operating on R13. Journal of Heat Recovery Systems, 11(2-3), 185-188.

Green, D. W.-ed. (1997). Perry's Chemical Engineers' Handbook $\left(7^{\text {th }}\right.$ ed.). New York, NY: McGraw-Hill Book Co.

Holland, F. A., Watson, F. A., Devotta, S. (1982). Thermodynamic Design Data for Heat Pump Systems. Oxford: Pergamon Press.

Jiang, J. A., Devotta, S., Watson, F. A., Holland, F. A. (1982). Derived Thermodynamic Design Data for Heat Pump Systems operating on R21. Journal of Heat Recovery Systems, 2(1), 37-55.

Jin, H., Spitler, J. D. (2002). Parameter Estimation Based Model of Water-to-Water Heat Pumps for use in Energy Calculation Program. ASHRAE Transactions. 18(1), 3 17. 
Mickley, H. S., Sherwood, T. K., Reed, C. E. (1957). Applied Mathematics in Chemical Engineering. (2 ${ }^{\text {nd }}$ ed.), New York, NY: McGraw-Hill Co Inc.

Olawale, A. S., Adefila, S. S. (2011). Rankine Heat Pumps' Performance as Temperature Lift Variables. AIChE Journal; 57(7), 1905-1911

Omideyi, D. A., Devotta, S.,Watson, F. A., Holland, F. A. (1983). Derived Thermodynamic Design Data for Heat Pump Systems operating on R290. Journal of Heat Recovery Systems, 3(2), 137-143.

Patwardhan, V. R., Patwardhan, V. S. (1987). A Simplified Procedure for Estimation of $(\mathrm{COP})_{\mathrm{R}}$ for Heat Pumps. Heat Recovery Systems and CHP, 7(5), 435 - 440

Poling, B. E., Prausnitz, J. M., O’Connell, J. P. (2001). The Properties of Gases and Liquids. ( $5^{\text {th }}$ ed.). New York, NY: McGraw-Hill Co. Inc..

Reay, D. A., Macmicheal, D. B. A. (1979) Heat Pump: Design and Application. Cambridge: Pergamon Press Ltd..

Srinivasan, P., Devotta, S., Watson, F. A., Holland, F. A. (1983). Derived Thermodynamic Design Data for Heat Pump Systems operating on R115. Journal of Heat Recovery Systems. 3 (4), 327-332.

\section{Appendix}

\section{A1. Formulation of the Model}

A1.1 Transformation of the enthalpy ratio

The Rankine coefficient of performance (COPR) is the ideal enthalpy change ratio of condensation and compression processes in vapour compression heat pump. That is:

$\operatorname{COPR}=(\Delta \mathrm{H})_{\mathrm{P}} /(\Delta \mathrm{H})_{\mathrm{S}}$

where: $(\Delta \mathrm{H})_{\mathrm{P}}$ is isobaric enthalpy change on condensation, $(\Delta \mathrm{H})_{\mathrm{S}}$ is isentropic enthalpy change on compression.

The differential fundamental property relation of enthalpy (closed system) is given as:

\section{$\mathrm{dH}=\mathrm{TdS}+\mathrm{VdP}$}

For simple substances and azeotropes, condensation (and evaporation) and compression could be represented respectively as (from Eq. (A.2)):

$$
(\mathrm{dH})_{\mathrm{T}, \mathrm{P}}=(\mathrm{TdS})_{\mathrm{T}, \mathrm{P}}
$$

and

$$
(\mathrm{dH})_{\mathrm{S}}=(\mathrm{VdP})_{\mathrm{S}}
$$

or in integral forms as:
$(\Delta \mathrm{H})_{\mathrm{P}}=\int(\mathrm{TdS})_{\mathrm{P}}$

Substituting Eqs. (A.4a) and (A.4b) in Eq. (A.1) gives:

$\mathrm{COPR}=\int(\mathrm{TdS})_{\mathrm{P}} /(\mathrm{VdP})_{\mathrm{S}}$

Noting that $(\partial \mathrm{T} / \partial \mathrm{P})_{\mathrm{S}}=(\partial \mathrm{V} / \partial \mathrm{S})_{\mathrm{P}}$ (a Maxwell equation), and multiplying the right hand side (RHS) of Eq. (A.5) by $(\partial \mathrm{P} / \partial \mathrm{T})_{\mathrm{S}}(\partial \mathrm{V} / \partial \mathrm{S})_{\mathrm{P}}$ gives:

$\mathrm{COPR}=\int(\mathrm{TdV})_{\mathrm{P}} /(\mathrm{VdT})_{\mathrm{S}}$

\section{A1.2 Formulated model}

The assumptions and approximations made in the formulation of the model are (a) phase transition occurs at constant temperature (i.e. no superheat) and (b) volume change with condensation approximates saturated vapour volume (i.e. $\mathrm{V}_{\mathrm{g}}-\mathrm{V}_{\mathrm{l}}=\mathrm{V}_{\mathrm{g}}$ ). Assumptions (a) and (b) respectively translate to Eqs. (A.7) and (A.8).

$\mathrm{COPR}=\mathrm{T} \int \frac{(\mathrm{dV})_{\mathrm{P}}}{(\mathrm{VdT})_{\mathrm{S}}}$

$\int(\mathrm{dV})_{\mathrm{P}} \cong \mathrm{V}_{\mathrm{g}} \cong \mathrm{zRT} / \mathrm{P}$

where: $\mathrm{V}_{\mathrm{g}}$ is saturated vapour specific or molar volume, $\mathrm{V}_{\mathrm{l}}$ is saturated liquid specific or molar volume, $\mathrm{T}$ is temperature, $\mathrm{P}$ is pressure, $\mathrm{z}$ is compressibility factor and $\mathrm{R}$ is gas constant.

$$
\text { Now: } \begin{aligned}
\mathrm{V}_{\mathrm{S}} & =\left(\frac{\partial \mathrm{H}}{\partial \mathrm{P}}\right)_{\mathrm{S}}, \quad\left(\frac{\partial \mathrm{H}}{\partial \mathrm{P}}\right)_{\mathrm{S}}=-\left(\frac{\partial \mathrm{H}}{\partial \mathrm{S}}\right)_{\mathrm{P}}\left(\frac{\partial \mathrm{S}}{\partial \mathrm{P}}\right)_{\mathrm{H}} \quad \text { and } \\
\mathrm{T} & =\left(\frac{\partial \mathrm{H}}{\partial \mathrm{S}}\right)_{\mathrm{P}} \Rightarrow \mathrm{V}_{\mathrm{S}}=-\mathrm{T}\left(\frac{\partial \mathrm{S}}{\partial \mathrm{P}}\right)_{\mathrm{H}}
\end{aligned}
$$

Isenthalpic curves in $\mathrm{P}-\mathrm{S}$ chart for pure substances are fairly linear (Green, 1997) and so a typical slope $(\partial S / \partial P)_{H}$ could be taken as a constant, $\mathrm{k}_{\mathrm{H}}$. Thus the integral form of the denominator of Eq. (A.7) is written as:

$\int(\mathrm{VdT})_{\mathrm{S}}=(-\partial \mathrm{H} / \partial \mathrm{P})_{\mathrm{H}} \cdot \int(\mathrm{TdT})_{\mathrm{S}}$

$\Rightarrow \mathrm{k}_{\mathrm{H}} \int_{\mathrm{T}_{\mathrm{EV}}}^{\mathrm{T}_{\mathrm{CO}}} \mathrm{TdT}=0.5 \mathrm{k}_{\mathrm{H}}\left(\mathrm{T}_{\mathrm{CO}}^{2}-\mathrm{T}_{\mathrm{EV}}^{2}\right)$

Substituting in Eq. (A.7) with Eqs. (A.8) and (A.9) gives

$\mathrm{COPR}=\frac{2 \mathrm{RZ}_{\mathrm{CO}}}{\mathrm{k}_{\mathrm{H}} \mathrm{P}_{\mathrm{CO}}} \frac{\mathrm{T}_{\mathrm{CO}}}{\mathrm{T}_{\mathrm{CO}}+\mathrm{T}_{\mathrm{EV}}} \frac{\mathrm{T}_{\mathrm{CO}}}{\mathrm{T}_{\mathrm{CO}}-\mathrm{T}_{\mathrm{EV}}}$

Eq. (A.10) is the formulated model obtained through transformation 